\title{
Uma proposta de avaliação alternativa e "autêntica" em educação pré-escolar: o Sistema de Acompanhamento das Crianças (SAC)
}

GABRIELA PORTUGAL Universidade de Aveiro

\section{INTRODUÇÃO}

Em Portugal, as Orientações Curriculares para a Educação Pré-Escolar (OCEPE) (Ministério da Educação, 1997) definem-se como um quadro de referência oficial, comum a todos os educadores, permitindo o desenvolvimento contextualizado de diferentes currículos, opções pedagógicas e práticas de avaliação.

As OCEPE "acentuam a importância de uma pedagogia estruturada, o que implica uma organização intencional e sistemática do processo pedagógico, exigindo que o educador planeie o seu trabalho e avalie o processo e os seus efeitos no desenvolvimento e na aprendizagem das crianças" (idem, p. 18). Continuando com o enunciado das OCEPE (idem, p. 25-28), a intencionalidade do processo educativo pressupõe observar, planear, agir, avaliar, comunicar e articular: observar cada criança e o grupo para conhecer as suas capacidades, interesses e dificuldades, recolher informações sobre o contexto familiar e o meio em que as crianças vivem, com vista à adequação do processo educativo; planear de acordo com o que o educador sabe do grupo e de cada criança, implicando reflexão sobre intenções educativas e as formas de as concretizar/adequar ao grupo e a cada criança, procurando criar situações de desafio ainda que acautelando situações de excessiva exigência e envolvendo as crianças no próprio planeamento; agir, concretizando na ação as intenções 
educativas; avaliar o processo e os efeitos, envolvendo as crianças e legitimando o planeamento futuro a realizar; comunicar e articular com colegas, auxiliares, pais, agentes da comunidade, apostando no trabalho em equipa e promovendo a continuidade educativa e transição para a escolaridade obrigatória.

No que remete às competências de observação, avaliação e planificação, o Perfil especifico de desempenho profissional do educador de infância (Direção-Geral..., 2001, decreto-lei n. 241/2001) vem acentuar o enunciado das OCEPE, referindo a importância de o educador conceber e desenvolver o respetivo currículo, por meio da planificação, organização e avaliação do ambiente educativo, bem como das atividades e projetos curriculares, com vista à construção de aprendizagens integradas. Aponta ainda a importância de o educador avaliar, numa perspetiva formativa, a sua intervenção, o ambiente e os processos educativos adotados, bem como o desenvolvimento e aprendizagens de cada criança e do grupo.

Mais recentemente, a definição de metas de aprendizagem para a educação pré-escolar (Ministério da Educação, 2010), enquanto referentes de gestão curricular a contextualizar em cada agrupamento ou escola, identifica competências e desempenhos esperados das crianças no final do período pré-escolar, no entendimento que tais competências ou desempenhos evidenciam a efetiva concretização das aprendizagens propostas nas OCEPE. Avaliar o desenvolvimento de competências e desempenhos em educação pré-escolar assume-se, assim, como um desafio premente.

Ainda mais recentemente, o Ministério da Educação (2011) emitiu uma circular relativa à avaliação em educação pré-escolar que procura conjugar as diferentes diretrizes oficiais no que à avaliação diz respeito, apresentando-a como processo contínuo de registo dos progressos realizados pela criança, ao longo do tempo, utilizando procedimentos de natureza descritiva e narrativa, centrados sobre o modo como a criança aprende, como processa a informação, como constrói conhecimento ou resolve problemas. Aponta ainda para a necessidade de avaliação do ambiente educativo, enquanto elemento promotor de aprendizagens, considerando, nesse processo, a organização do espaço, dos materiais e dos recursos educativos; a diversidade e qualidade dos materiais e recursos educativos; a organização do tempo; as interações do adulto com a criança e entre crianças; o envolvimento parental; as condições de segurança, de acompanhamento e bem-estar das crianças. Essa mesma circular refere que, de acordo com as suas conceções e opções pedagógicas, cada educador poderá utilizar técnicas e instrumentos de observação e registo diversificados.

Sendo esse o contexto oficial da avaliação em educação pré-escolar, em Portugal, o que é que se sabe sobre a realidade das práticas de avaliação em educação pré-escolar? Ao mesmo tempo, que práticas avaliativas alternativas em educação de infância são desejáveis e/ou recomendadas pela literatura da especialidade? Neste artigo, para além de pretendermos abordar essas questões, procuramos apresentar e enquadrar conceptualmente uma abordagem avaliativa denominada Sistema de Acompanhamento das Crianças (SAC) (Portugal; Laevers, 2010) que oferece possibilidades de avaliação alternativa e/ou "autêntica" (Bagnato, 2005, 2007; Epstein et al., 2004; Neisworth; Bagnato, 2004), respondendo plenamente às orientações oficiais e aos atuais consensos científicos sobre qualidade educativa. Finalmente, destacaremos alguns efeitos gerados pelo seu uso na intervenção educacional. 


\section{O QUE É QUE SE SABE SOBRE A REALIDADE DAS PRÁTICAS DE AVALIAÇÃO EM EDUCAÇÃO PRÉ-ESCOLAR, EM PORTUGAL?}

Apesar do seu enquadramento normativo, em Portugal verifica-se uma grande heterogeneidade no pensamento e nas práticas de avaliação. À avaliação aponta-se a sua complexidade e subjetividade e invoca-se, frequentemente, a falta de tempo, de recursos e, muitas vezes, desconhecimento na utilização de procedimentos adequados de observação, registo e avaliação, quer dos processos, quer dos efeitos, para justificar a sua secundarização nas práticas pedagógicas pré-escolares.

$\mathrm{Na}$ verdade, o nosso conhecimento de algumas experiências educativas no pré-escolar diz-nos que os educadores de infância têm uma necessidade clara de aperfeiçoamento de competências de avaliação, que lhes permita afirmar a sua especificidade, articulando e respondendo às exigências do nível de ensino seguinte ( $1^{\circ}$ ciclo) e às necessidades organizacionais da escola.

Alguns estudos nacionais sobre avaliação em educação de infância (por exemplo, Carvalho, 2007; Gonçalves, 2008; Leal, 2011; Pinheiro, 2009) têm evidenciado a falta de formação dos educadores na área da avaliação, sendo esta, em geral, associada a dificuldades, desconforto e tensões, havendo um receio de avaliar mal e colocar rótulos às crianças. Do mesmo modo, Oliveira-Formosinho e Parente (2005, p. 28), referindo-se aos estudos realizados no âmbito do Projeto Infância e Associação Criança junto de educadores, dizem que "perante esforços de debater a questão da avaliação surgiram os receios de que esta representasse uma 'escolarização precoce' e/ou uma 'rotulagem". Assinalam-se, também, dificuldades ao nível da organização da atividade de avaliação e preocupação com a definição de critérios/indicadores de avaliação (Leal, 2011; Oliveira-Formosinho; Parente, 2005; Pinheiro, 2009). Analisando conceções e práticas de avaliação em educação de infância, as conclusões do estudo de Maia (2007) vão ao encontro dos resultados de Gonçalves (2008, p. 214), que conclui que "do ponto de vista praxeológico, nem sempre as práticas avaliativas formais correspondem às conceções curriculares dos educadores, especificamente no que se refere à adequação dos instrumentos formais de avaliação ao pré-escolar e ao tipo de informação sistematizada”. Também o estudo de Oliveira e Gaspar (2004) aponta para a existência de práticas de avaliação não sistemáticas e, sobretudo, de carácter informal, mas também manifesto interesse das educadoras em alterarem as suas práticas de avaliação. $\mathrm{O}$ trabalho de Fernandes (2009) corrobora o interesse e valorização da componente avaliativa no processo de desenvolvimento curricular, sendo a avaliação considerada o motor de aperfeiçoamento do trabalho pedagógico dos educadores.

A recolha de diferentes instrumentos de avaliação utilizados e partilhados entre a comunidade de educadores, por nós efetuada no contexto do trabalho junto de diversos jardins de infância portugueses, evidencia uma profusão de procedimentos estandardizados, na sua maioria consubstanciados em checklists de capacidades isoladas e atomizadas, procurando a objetividade da medida. Ressalta, assim, uma abordagem bem distanciada da ideia "not everything that counts can be counted and not everything that can be counted, counts" (Einstein), ou seja, bem distanciada de uma avaliação "autêntica" e útil (Bagnato, 2005, 2007). De acordo com esse autor, a avaliação convencional que tem dominado no campo da educação de infância, da intervenção precoce e da educação 
especial, não tem servido os seus objetivos (conhecer as competências das crianças nos seus contextos e rotinas habituais, apoiar o delineamento de programas de intervenção e documentar o processo de desenvolvimento das crianças), desconsiderando as práticas de avaliação alternativas recomendadas pela literatura especializada.

\section{QUE PRÁTICAS AVALIATIVAS ALTERNATIVAS?}

A verificação ou medida das aprendizagens releva de uma perspetiva tradicional de avaliação (Carr,2001; Oliveira-Formosinho; Parente, 2005; Pinto,2005) que tem sido posta em causa por vários estudos e autores. A avaliação em educação de infância, quando é feita, como vimos, continua muito dominada pelo uso de instrumentos normativos, direcionados para a identificação do défice, ignorando a componente interativa, social e cultural de um processo de ensino-aprendizagem que parte de uma imagem positiva da criança, com interesses e recursos únicos. $\mathrm{O}$ abandono de práticas de avaliação descontextualizadas que ignoram a individualidade e irrepetibilidade de cada criança e a procura de abordagens que captem a unicidade e autenticidade de cada criança, considerando o seu desenvolvimento nos contextos e rotinas naturais de vida, permanece um desafio importante e atual. Avaliar o desenvolvimento de uma criança não se pode limitar a inventariar capacidades adquiridas, em vias de aquisição ou ainda inexistentes. Esse tipo de avaliação sumativa pode conduzir a uma constatação interessante e, por vezes, até necessária, mas não suficiente e aquém de uma avaliação dinâmica, contextualizada, ao serviço do desenvolvimento e da educabilidade das pessoas.

Sabemos bem que as competências das crianças mais novas são dependentes da situação ou contexto, não se coadunando com os constrangimentos impostos por uma checklist estandardizada. Uma avaliação e monitorização contínua no decurso da experiência de jardim de infância configuram-se como uma abordagem mais autêntica, fidedigna e respeitadora do desenvolvimento e aprendizagem das crianças. Neisworth e Bagnato (2004) definem avaliação autêntica como o processo de recolha sistemática de informações, feito por adultos próximos e que conhecem bem as crianças, sobre os seus comportamentos nos seus contextos naturais de vida (casa ou jardim de infância), sendo considerada a funcionalidade desses comportamentos e as crianças encorajadas a demonstrar competências em diversas e múltiplas situações (versus procedimentos estandardizados e descontextualizados).

Segundo Epstein et al. (2004), uma avaliação adequada ou autêntica em educação de infância deve satisfazer um conjunto de critérios de que destacamos as seguintes ideia:

1) A avaliação não deve criar ansiedade ou medo na criança, não pondo em causa a sua autoestima, nem dando azo a um sentimento de insucesso; a avaliação deve atender ao que as crianças conhecem e são capazes, e nunca ser penalizadora pelo que elas não sabem.

2) A informação deve ser obtida ao longo do tempo, em múltiplas e significativas situações, no contexto das atividades naturais da criança.

3) $O$ valor da avaliação vai muito além da focalização no desenvolvimento e aprendizagens das crianças; a avaliação é indispensável na análise da qualidade da oferta educativa e na compreensão da forma como esta vai, ou não, ao en- 
contro das necessidades das crianças, atendendo ao seu bem-estar e implicação nas atividades, sendo crucial a todo o planeamento e processo de melhoria.

É nessa linha de pensamento que Drummond (2005, p. 19) refere que uma avaliação com sentido é aquela em que se aprecia e compreende

[...] o que as crianças sabem, reconhecemos os seus sucessos, as suas características individuais e as diferenças entre crianças. Podemos usar estas avaliações para organizar e enriquecer o currículo, as nossas interações com as crianças e as respostas educativas no seu todo. Essas avaliações também podem servir para identificar o que a criança vai ser capaz de aprender a seguir, de forma a apoiarmos e a alargarmos a sua aprendizagem. A avaliação das aprendizagens das crianças faz parte da procura de qualidade, na nossa prática diária.

No fundo, trata-se da ideia de Gaspar (2005, p. 55): "avaliar é tomar consciência para adaptar", significa sintonizarmo-nos com a criança, recolhendo informação sobre o seu processo de aprendizagem e de desenvolvimento e utilização da informação para apoiar e amplificar a aprendizagem.

Advogando uma avaliação formativa, que serve a adaptação do ensino às necessidades da criança, Hatch (2010) assume que a avaliação não tem de ser algo que surge separado do currículo e do processo de ensino, não tem de ser estéril ou ameaçadora. Deve estar presente em qualquer atividade de aprendizado e fundamentar qualquer reorientação no processo de ensino e aprendizagem. Esse autor recorre também à ideia de avaliação dinâmica, baseada no conceito de Zona de Desenvolvimento Próximo (ZDP), de Vygotsky. Trata-se de um importante conceito na área da avaliação "autêntica" (Portugal et al., 2010; Sweeney, 2007). Pela observação da criança e atendendo ao seu vivido, o educador pode inferir a sua $Z \mathrm{DP}$ e estimular a criança a progredir e aceder a níveis de funcionamento mais avançados e complexos. O conceito de ZDP, quando devidamente apropriado pelos educadores, potencia avaliações significativas e realísticas, focalizadas nos passos e estratégias a adotar no processo de ensino e aprendizagem. Como Vygotsky (1984/1996, p. 268), assume-se que o profissional que se limita a atender ao nível de desenvolvimento real da criança comete o mesmo erro do horticultor que, ao calcular a colheita de uma estação, tem apenas em conta a fruta já madura. Ao investigar o que a criança já consegue fazer por si só, atende ao desenvolvimento do dia anterior; ao focalizar-se no que a criança pode fazer em interação com um contexto físico e relacional estimulante, atende ao desenvolvimento de amanhã. Assim, a abordagem avaliativa de Vygotsky inclui a determinação do nível real e potencial de desenvolvimento, bem como a qualidade das interações que vão permitir que o nível potencial se converta em real. Assume-se que para o progresso da criança é fundamental a relação entre o nível de preparação e de desenvolvimento desta e o nível de exigências efetuadas pela escola (Vygotsky, 1933 apud Van der Veer; Valsiner, 1991). Para Vygotsky, os professores devem colaborar com as crianças em atividades cognitivas conjuntas que deverão ser escolhidas de modo que se adéquem ao nível de desenvolvimento potencial da criança. $\mathrm{O}$ ensino só é considerado bom quando vai à frente do desenvolvimento e desperta para a vida aquelas funções que estão em processo de amadurecimento ou na 
ZDP (Vygotsky, 1956 apud Wertsch; Stone, 1985). Na abordagem de Bruner (1985), a tarefa do educador consiste em "construir andaimes" (scaffolding), ou seja, reduzir o número de graus de liberdade com que a criança tem de lidar na realização da tarefa. Depois de a criança dominar aspetos básicos da tarefa, o educador incentiva a criança a utilizar essas competências para avançar para algo mais complexo. Este princípio que consiste em aumentar gradualmente a exigência é o que mantém a criança na ZDP ("região de sensibilidade ao ensino"). Assim, os educadores mais eficazes centram a sua atividade na região de sensibilidade, mantendo elevados níveis de implicação da criança. De acordo com essa leitura, e estabelecendo uma ligação com a abordagem experiencial da educação (Laevers, 2003; Laevers; Van Sanden, 1997), assume-se uma relação muito estreita entre ZDP e níveis de implicação elevados. A implicação é definida por Laevers como uma qualidade da atividade humana que pode ser reconhecida pela concentração e persistência, caraterizando-se por motivação, interesse e fascínio, abertura aos estímulos, satisfação e um intenso fluxo de energia. A implicação é determinada pela necessidade de exploração e pelo nível de desenvolvimento, estando na base de aprendizagens significativas e do processo de desenvolvimento.

Se estar implicado significa movermo-nos nos limites das nossas capacidades, ainda que não saibamos exatamente quais são esses limites, é possível deduzir, pelo nível de implicação da criança, se ela está ou não a ativar os seus atuais e potenciais talentos, se está a agir em ZDP.

Prestar atenção à qualidade de implicação da criança e perceber o que significa para ela experienciar um determinado contexto educacional (processo de reconstrução da experiência da criança), não sendo fácil, é o que parece verdadeiramente estar na base de uma avaliação e intervenção educativa qualitativamente superior. A adoção de uma atitude experiencial pressupõe a capacidade de o adulto colocar-se na perspetiva da criança (e em consonância, ir mais devagar, dizer por outras palavras, propor outra abordagem, diversificar as atividades etc.), mobilizando na relação dimensões como a empatia e intuição (Laevers, 1998, 2003) e criando condições de ensino efetivamente conducentes a aprendizagens. Este papel em que o adulto, em conjunto com a criança, cria uma zona de desenvolvimento próximo e garante aprendizagens, requer a mais alta competência do educador (Portugal, 2009).

Cabe ao adulto educador/professor identificar o potencial desenvolvimental e educacional inerente às atividades, pensar e disponibilizar situações estimulantes, formulando "pontos de atenção" e atendendo ao bem-estar emocional e implicação das crianças (Portugal; Laevers, 2010, p. 41). Cabe-lhe ainda, e na linha do que refere Roldão (2003, p. 57), "a competência de criar e conceber as situações que realmente servem para demonstrar se o aprendente se tornou ou não competente", isto é, "se é capaz de mobilizar adequadamente diversos conhecimentos prévios, selecioná-los e integrá-los adequadamente perante [uma] situação (ou problema, ou questão, ou objeto cognitivo ou estético etc.)"(idem, p. 20).

Cabe igualmente ao adulto a tarefa de se questionar e refletir: todas as crianças recebem suficiente estímulo, calor e atenção? Todas as crianças se desenvolvem bem, em todas as áreas do desenvolvimento, ou algumas áreas são negligenciadas ou subvalorizadas? Ou, será a oferta educativa pautada pela homogeneização construída à volta de uma criança hipotética média que não existe? 
Se a base para a progressão e o alargamento dos saberes das crianças se encontra nas próprias crianças, é o processo reflexivo de observação e avaliação que permitirá ao educador adequar a sua prática às atuais capacidades, necessidades e perspetivas das crianças. Nesse processo, levantam-se desafios que passam pela atenção à experiência da criança (perscrutando cognições, emoções, motivações...) e compreensão da diversidade das infâncias (cultura, desenvolvimento, vivências...), procurando articular e integrar num espaço de vida coletivo a diversidade de interesses e necessidades individuais.

É tarefa do adulto envolver ou implicar as crianças nas atividades, procurando compreender o que realmente as mobiliza, que questões se lhes levantam, o que realmente é importante para elas.

Atualmente, a importância da promoção de uma cidadania ativa (Lansdown, 2005; Libório, 2010; Moss, 2007) é assumida por vários autores, acentuando-se a necessidade de escutar as crianças, conhecer os seus sentimentos e pensamentos, aceder às suas opiniões e ideias. $\mathrm{Na}$ linha do artigo $12^{\circ} \mathrm{da}$ Convenção sobre os Direitos das Crianças (Assembleia-Geral..., 1989) lê-se que a criança tem direito de exprimir as suas opiniões em todas as questões que lhe digam respeito, devendo essas opiniões ser tomadas em devida consideração. Assim, na senda de trabalhos de autores como Brougère, Vandenbroeck, Tobin, Dahlberg, Moss, Rogoff e outros (in Brougère; Vandenbroeck, 2007), também no processo de avaliação temos assistido à atribuição de um maior protagonismo da criança, tendo-se procurado escutá-la, conhecer e valorizar a sua "agência" (Libório, 2010). Vasconcelos (2006) refere que a concretização da ideia de "agência" implica que a criança se sinta ativa, com um sentido do seu próprio poder, sentindo-se implicada e envolvida, sentindo que "vale a pena" e é "importante", e, portanto, capaz de dar um contributo para a vida social.

Fica o desafio de conjugar todas essas ideias num instrumento ou abordagem avaliativa mais "autêntica", dinâmica e alternativa às práticas convencionais. A nossa proposta é o SAC (Portugal; Laevers, 2010).

\section{O SISTEMA DE ACOMPANHAMENTO DAS CRIANÇAS (SAC)}

Considerando a realidade da avaliação em educação pré-escolar em Portugal e atendendo ao que é esperado oficialmente e preconizado pela literatura especializada, no Departamento de Educação da Universidade de Aveiro (Portugal), desenvolveu-se um projeto ${ }^{1}$ visando à construção de um instrumento para apoio à prática pedagógica, facilitando a relação entre as práticas de observação, avaliação e edificação curricular, procurando assegurar uma avaliação "autêntica" e dinâmica.

Tendo como base a abordagem experiencial em educação (Laevers, 1998, 2004; Laevers; Van Sanden, 1997) e o trabalho de Laevers et al. (1997), o SAC estrutura-se em torno do princípio de que a avaliação deve ser processual e deve tornar possível o desenvolvimento de práticas orientadas não apenas para efeitos ou resultados (aprendizagens e desenvolvimento de competências das crianças), mas também para a melhoria

1 Projeto financiado pela Fundação para a Ciência e Tecnologia (FCT) - (PTDC/ $\mathrm{CED} / 67633 / 2006)$. 
do contexto educativo. Nessa linha de pensamento, inspirado no Process-Oriented Monitoring System for young children (POMS) (Laevers et al., 1997), o SAC foi trabalhado e adaptado à realidade portuguesa, ao longo de três anos letivos, no contexto da prática pedagógica supervisionada da licenciatura em educação de infância, integrando a cultura e orientações oficiais portuguesas; a participação da criança na avaliação e no desenvolvimento do currículo; e indicadores de qualidade do contexto, dos processos vivenciados pelas crianças (níveis de bem-estar emocional e de implicação) e do desenvolvimento de competências (na linha do proposto nas orientações oficiais).

No que respeita à forma como as crianças se desenvolvem e aprendem, o SAC: (1) pretende promover práticas que são guiadas por princípios socioconstrutivistas e experienciais; (2) considera que a educação ocorre em interação e é um diálogo entre crianças e entre crianças e adultos; e (3) assume que as crianças são competentes e cidadãos plenos, mas que precisam do apoio dos adultos, marcado pelo respeito e escuta, estimulando, criando andaimes, e conferindo uma autonomia crescente à criança (procurando uma ação na ZDP).

Adotando essas perspetivas, no SAC considera-se que a orientação para o bem-estar emocional e implicação ou envolvimento responde bem à questão essencial: até que ponto, nesse contexto preciso, a criança $x$ ou $y$ se desenvolve? O nível real de desenvolvimento é irrelevante se os educadores não atenderem ao nível potencial de desenvolvimento (em parte, lido pelos níveis de implicação), que pode ser ativado em interações com e com o apoio de um parceiro mais capaz (adulto ou outra criança).

"Responder bem" a todas e a cada criança é um dos objetivos que caracteriza o $\mathrm{SAC}$,implicando ter em consideração as circunstâncias de vida das crianças, o que tem relação com o reconhecimento das culturas e subculturas da comunidade e das famílias. Essa perspetiva exige atenção e aceitação da diversidade, bem como a individualização do currículo - uma perspetiva "centrada na criança" que exige questionamento constante das práticas, pensamento crítico e mentes abertas.

De acordo com a abordagem experiencial, a maneira mais económica e conclusiva para avaliar a qualidade em qualquer contexto de ensino é concentrar-se em duas dimensões: bem-estar emocional e nível de implicação experienciados pelas crianças (Laevers, 2003). O modelo experiencial oferece uma forma respeitadora de sentir, pensar e fazer em educação infantil, uma abordagem centrada na criança, em que o adulto tem, como ponto de referência inicial, a experiência da criança (lida por meio da análise do seu bem-estar emocional e implicação), reconstruindo significados por meio de suas expressões, palavras e gestos. As intervenções baseiam-se na iniciativa e autonomia da criança, num ambiente enriquecido e estimulante e no desenvolvimento de um diálogo sensível e atento. Promover o bem-estar e participação da criança conduz ao objetivo último de assegurar o seu desenvolvimento pessoal e social.

\section{AVALIAÇÃO PROCESSUAL - IMPLICAÇÃO E BEM-ESTAR EMOCIONAL}

Como refere Laevers (idem, p. 14),

quando queremos saber como cada uma das crianças está num contexto, primeiro temos que explorar o grau em que as crianças se sentem à vontade, agem espontanea- 
mente, mostram vitalidade e autoconfiança. Tudo isso indica que o seu bem-estar emocional está $\mathrm{OK}$ e que as suas necessidades físicas, a necessidade de ternura e afeto, a necessidade de segurança e clareza, a necessidade de reconhecimento social, a necessidade de se sentir competente e a necessidade de sentido na vida e valores morais estão satisfeitos. O segundo critério está relacionado com o processo de desenvolvimento e leva o adulto a criar um ambiente desafiador, que favorece a implicação.

Os níveis de bem-estar e de implicação tornam-se pontos de referência para os profissionais que pretendem melhorar a qualidade do seu trabalho, que querem promover o desenvolvimento e a aprendizagem. Nesse sentido, Laevers desenvolveu escalas para avaliação, quer do bem-estar emocional, quer da implicação, escalas essas que são integradas no SAC.

$\mathrm{Na}$ escala de avaliação do bem-estar emocional, este é observado e descrito em cinco níveis diferentes, num continuum desde o nível muito baixo, em que há claros sinais de sofrimento emocional, até um nível muito alto, em que as crianças evidenciam estar bem consigo próprias e com o mundo envolvente. Assume-se que o grau de bem-estar indica o quanto o ambiente educativo ajuda as crianças a se sentirem em casa, a serem elas mesmas e a ter as suas necessidades emocionais preenchidas (confiança, atenção, reconhecimento e sentido de competência) (Laevers et al., 2005).

A escala de envolvimento/implicação para crianças (Leuven Involvement Scale for Young Children - LIS-YC) (Laevers, 1994) permite aos educadores observar e avaliar o envolvimento ou implicação numa escala de cinco pontos.

No nível 1, não há atividade. A criança está mentalmente ausente. Se podemos observar alguma ação é meramente uma repetição de movimentos estereotipados muito elementar. O nível 2 não vai muito mais longe, assinalando ações com muitas interrupções. No nível 3, podemos, sem dúvida, observar no comportamento da criança uma atividade. A criança está fazendo alguma coisa... mas não existe concentração, motivação e verdadeiro prazer na atividade. Em muitos casos, a criança está a funcionar num nível de rotina. No nível 4 ocorrem momentos de intensa atividade mental. No nível 5 o envolvimento é total, expresso na concentração e implicação absolutas. Qualquer perturbação ou interrupção é vivida como uma rutura frustrante de uma atividade que está a fluir. (Laevers, 2003, p. 16)

\section{AVALIAÇÃO DE EFEITOS OU RESULTADOS}

No SAC, a análise do desenvolvimento de competências (Portugal; Laevers, 2010) centra-se em atitudes - autoestima, auto-organização e iniciativa; no comportamento do grupo e/ou competência social; e em aquisições básicas - motricidade fina e grossa, expressão artística, linguagem, pensamento lógico, conceptual e matemático, e compreensão do mundo físico/tecnológico e social. A curiosidade e a vontade de aprender (ímpeto exploratório), criatividade e ligação ao mundo são atitudes consideradas implícitas e transversais a todas as áreas referidas. Trata-se de uma abordagem que vai ao encontro do referenciado, quer nas OCEPE (Ministério da Educação, 1997, p. 49), 
quer na Metas de Aprendizagem para a Educação Pré-Escolar (Ministério da Educação, 2010). Efetivamente, de acordo com as OCEPE, é finalidade da educação pré-escolar organizar um conjunto de experiências a partir das quais as crianças aprendem e desenvolvem competências pessoais e sociais. O desenvolvimento pessoal e social enquanto área integradora do processo educativo tem que ver com a forma como a criança se relaciona consigo própria, com os outros e com o mundo, num processo que implica o desenvolvimento de atitudes e valores, atravessando as áreas de expressão e comunicação, e de conhecimento do mundo. Ainda, segundo as OCEPE (p. 90),

distinguem-se 3 tipos de condiçôes favoráveis para que cada criança possa iniciar o $1^{\text {o }}$ ciclo com possibilidades de sucesso: as que dizem respeito ao comportamento da criança no grupo, as que implicam determinadas aquisições indispensáveis para aprendizagem formal da leitura, escrita e matemática, e as que se relacionam com atitudes.

Essas competências pessoais e sociais podem ser articuladas com as Metas de Aprendizagem para a Educação Pré-Escolar (2010), de acordo com o seguinte quadro:

Quadro 1 -Articulação entre competências pessoais e sociais e metas de aprendizagem para a educação pré-escolar

\begin{tabular}{|c|c|}
\hline $\begin{array}{c}\text { OCEPE - SAC } \\
\text { Desenvolvimento Pessoal e Social }\end{array}$ & $\begin{array}{l}\text { Metas de Aprendizagem para a } \\
\text { Educação Pré-Escolar }\end{array}$ \\
\hline $\begin{array}{l}\text { Atitudes } \\
\text { Autoestima positiva } \\
\text { Auto-organização/iniciativa } \\
\text { Curiosidade e desejo de aprender } \\
\text { Criatividade } \\
\text { Ligação ao mundo } \\
\end{array}$ & \multirow{2}{*}{$\begin{array}{l}\text { Área da formação pessoal e social } \\
\text { Identidade/autoestima } \\
\text { Independência/autonomia } \\
\text { Cooperação } \\
\text { Convivência democrática/cidadania } \\
\text { Solidariedade/Respeito pela diferença }\end{array}$} \\
\hline $\begin{array}{l}\text { Comportamento no grupo } \\
\text { Competência social }\end{array}$ & \\
\hline $\begin{array}{l}\text { Domínios essenciais } \\
\text { Motricidade fina } \\
\text { Motricidade grossa } \\
\text { Expressões artísticas } \\
\text { Linguagem } \\
\text { Pensamento lógico conceptual e matemático } \\
\text { Compreensão do mundo físico e tecnológico } \\
\text { Compreensão do mundo social }\end{array}$ & $\begin{array}{l}\text { Outras áreas e domínios } \\
\text { Expressões (motora, plástica, } \\
\text { musical, dramática e dança) } \\
\text { Linguagem oral e abordagem à escrita } \\
\text { Matemática } \\
\text { Conhecimento do mundo } \\
\text { Tecnologias de informação e comunicação }\end{array}$ \\
\hline
\end{tabular}

Fonte: ME, 1997, 2010.

Elaboração da autora.

\section{AVALIAÇÃO E INTERVENÇÃO DO/NO CONTEXTO EDUCATIVO}

A utilização do SAC envolve a dinamização de um ciclo contínuo de observação, avaliação, reflexão e ação focalizado no bem-estar, implicação, aprendizagem e desenvolvimento das crianças. Integra a análise de forças e áreas de fragilidade que necessitam de atenção e intervenção priorizadas, as opiniões das crianças relativamente às "coisas que lhes dizem respeito", a escuta de outros parceiros educativos (como as famílias) e a conceção e o desenvolvimento de estratégias de intervenção 
e de organização do ambiente educativo que melhor parecem responder às características e expectativas do contexto e das crianças.

Os ciclos de observação e reflexão inerentes ao SAC comportam três fases. Essas fases interligam-se e depois da fase 3 inicia-se um novo ciclo por meio de uma nova avaliação de todas as crianças, seguida de uma análise mais específica do contexto e de crianças em particular, identificando-se novos objetivos... e assim sucessivamente. $\mathrm{O}$ seguinte esquema procura ilustrar a sequência de todo o processo.

\section{Quadro 2 -Sequenciação dos ciclos e fases do SAC}

\begin{tabular}{|c|c|c|}
\hline FASES & Ações para o Grupo e Contexto & Ações Individualizadas \\
\hline $\begin{array}{l}\text { Fase } 1 \\
\text { Setembro - Outubro }\end{array}$ & $\begin{array}{l}\text { Caracterização geral do contexto } \\
\text { Avaliação geral do grupo } \\
\text { (implicação e bem-estar) }\end{array}$ & - \\
\hline Fase 2 & Análise geral do grupo e contexto & $\begin{array}{l}\text { Análise } \\
\text { individualizada }\end{array}$ \\
\hline Fase 3 & $\begin{array}{l}\text { Objetivos/iniciativas } \downarrow \\
\text { gerais }\end{array}$ & $\begin{array}{l}\text { Objetivos/iniciativas } \vee \\
\text { individualizadas }\end{array}$ \\
\hline $\begin{array}{l}\text { Fase } 1 \\
\text { Dezembro - Janeiro }\end{array}$ & $\begin{array}{l}\text { Avaliação geral do grupo } \\
\text { (implicação e bem-estar) }\end{array}$ & $\begin{array}{ll} & \text { Avaliação } \\
\text { desenvolvimental } \\
\text { individualizada de todas } \\
\text { as crianças (opcional) }\end{array}$ \\
\hline Fase 2 & Análise geral do grupo e contexto & $\begin{array}{l}\text { Análise } \\
\text { individualizada }\end{array}$ \\
\hline Fase 3 & $\begin{array}{l}\text { Objetivos/iniciativas } \downarrow \\
\text { gerais }\end{array}$ & $\begin{array}{l}\text { Objetivos/iniciativas } \vee \\
\text { individualizadas }\end{array}$ \\
\hline $\begin{array}{l}\text { Fase } 1 \\
\text { Março-Abril }\end{array}$ & $\begin{array}{l}\text { Avaliação geral do grupo } \\
\text { (implicação e bem-estar) }\end{array}$ & \begin{tabular}{|l} 
Avaliação \\
desenvolvimental \\
individualizada de todas \\
as crianças (opcional)
\end{tabular} \\
\hline Fase 2 & Análise geral do grupo e contexto & $\begin{array}{l}\text { Análise } \\
\text { individualizada }\end{array}$ \\
\hline Fase 3 & $\begin{array}{l}\text { Objetivos/iniciativas } \\
\text { gerais }\end{array}$ & $\begin{array}{l}\text { Objetivos/iniciativas } \vee \\
\text { individualizadas }\end{array}$ \\
\hline $\begin{array}{l}\text { Fase Final } \\
\text { Junho - Julho }\end{array}$ & $\begin{array}{l}\text { Avaliação geral do grupo } \\
\text { (implicação e bem-estar) }\end{array}$ & $\begin{array}{l}\text { Avaliação } \\
\text { desenvolvimental } \\
\text { individualizada de } \\
\text { todas as crianças }\end{array}$ \\
\hline
\end{tabular}

Fonte: Adaptação de Portugal; Laevers (2010, p. 76).

Elaboração da autora.

De uma forma sumária as três fases envolvem:

Fase 1: Observação e avaliação geral do contexto e de todo o grupo de crianças considerando níveis de implicação e de bem-estar emocional das crianças, identificando desde logo aquelas crianças que suscitam preocupação pelo facto de apresentarem níveis de bem-estar emocional e/ou de implicação baixos (em risco de desenvolvimento). Envolve uma caracterização geral do contexto do jardim de infância que visa reunir informação sobre características e recursos da comunidade, características e expectativas das famílias, bem como finalidades definidas no projeto curricular do estabelecimento/escola. Envolve também uma avaliação geral das crianças do grupo, 
focalizada nos níveis de bem-estar e de implicação. $\mathrm{Na}$ análise do grupo, o educador pode assinalar, entre outras possibilidades, as particularidades de algumas crianças, problemas ou dificuldades específicas, que só por si poderão ser, ou não, motivo para as crianças serem assinaladas como necessitando de uma análise mais específica. Cabe ao educador decidir se uma criança, apesar de exibir níveis adequados de implicação e bem-estar, por ser uma criança de risco, por exemplo, deverá ser assinalada como preocupante. A esse propósito, importa referir que pode suceder uma criança apresentar problemas de desenvolvimento, mas evidenciar elevados níveis de implicação em atividades. Nesse caso, e de acordo com a leitura experiencial, sabemos que a criança estará a funcionar no limite das suas atuais capacidades (em ZDP). Podemos não saber exatamente quais são esses limites, mas, se a criança está implicada, é porque a atividade vem ao encontro do que ela necessita, achando o estímulo adequado no contexto educativo, beneficiando-se dele. Então, não há motivo de preocupação e, em termos imediatos, não será necessário intervir. Pelo contrário, podemos verificar que crianças sem problemas de desenvolvimento não se interessam pelas atividades. Nesse caso, as crianças não encontram no contexto educativo o nível de estimulação ou de desafio de que necessitam para ativar e mobilizar novas competências, ou seja, o seu desenvolvimento está em risco, sendo necessário intervir. Se é na ausência de implicação e bem-estar que o desenvolvimento está ameaçado, podemos ter crianças muito talentosas que não encontram no contexto educativo desafios estimulantes, necessitando de atenção especial e devendo ser consideradas crianças preocupantes, em risco de estagnação desenvolvimental.

Em geral, crianças com níveis elevados/baixos de implicação apresentam também níveis elevados/baixos de bem-estar, pois existe uma relação muito íntima entre implicação e bem-estar. A criança que se sente emocionalmente abatida ou infeliz terá muito mais dificuldade em aderir a uma atividade e em experienciar alta implicação. As suas dificuldades emocionais não the deixam espaço mental para investimentos cognitivos. Por sua vez, a criança que não encontra estímulo ou desafio adequado nas atividades em oferta (porque demasiado aborrecidas, repetidas, fáceis ou demasiado difíceis) também terá dificuldades em se implicar e facilmente se sentirá aborrecida, desgostada, impaciente, zangada, conhecendo estados psicológicos facilmente conducentes a problemas de comportamento.

Fase 2: Análise e reflexão sobre a observação e avaliação anteriores, procurando perceber a relação entre níveis de implicação e de bem-estar e a organização do ambiente educativo, quer para o grupo em geral, quer para as crianças que suscitam inquietação. Esta fase integra, assim, duas abordagens: uma direcionada ao grupo e contexto e outra direcionada às crianças que suscitam preocupação. Em relação ao grupo e contexto, $o$ educador é convidado a pensar em aspetos positivos e em aspetos preocupantes, seja no nível do comportamento das crianças em geral, seja no nível de dimensões do jardim de infância ou da sala, oferta educativa, clima de grupo, espaço para iniciativa, organização e nas suas próprias características.

$\mathrm{Na}$ base das suas preocupações, o educador identifica fragilidades da oferta educativa e, em razão disso, delineia áreas de trabalho. Assim, quando avalia o contexto e procura explicações para os níveis baixos ou altos de implicação e bem-estar emocional, pode considerar importantes componentes (variáveis contextuais), pensar e conceber estratégias de mudança, em diferentes níveis. 
No nível da oferta educativa, o educador poderá questionar-se "até que ponto o contexto educativo é 'rico', apelativo e diversificado?”. Olha a organização dos espaços, os materiais lúdicos disponíveis e as atividades em oferta no decurso do dia; analisa o que provocam na criança em termos de aprendizagens e desenvolvimento. De forma consequente, procura enriquecer o meio educativo a fim de torná-lo mais atraente e mais rico em possibilidades de exploração.

No nível do clima de grupo, o questionamento procura induzir reflexão sobre a forma como as crianças se sentem no contexto e grupo - "até que ponto as crianças se sentem à vontade" - e perceber a qualidade das relações ali existentes (entre as crianças e com o adulto). Esse exercício tem evidenciado a importância de uma grande atenção à forma como os adultos modelam competências sociais positivas (por exemplo, são gentis, escutam, estabelecem relações empáticas e cooperantes), ajudam as crianças a desenvolver competências sociais apropriadas na interação com as outras crianças (por exemplo, ajudam as crianças a conversar sobre os conflitos em vez de se agredirem; encorajam as crianças mais tímidas e isoladas a encontrarem amigos; ajudam as crianças a perceber os sentimentos dos outros) e providenciam oportunidades de trabalho conjunto entre as crianças com vista à realização de projetos comuns e significativos, desenvolvendo um sentimento de pertença nas crianças.

Considerar o espaço para iniciativa/autonomia implica olhar as oportunidades que existem para as crianças decidirem o que vão fazer, com que frequência, com quem, bem como perceber de que forma é escutada a opinião da criança acerca da oferta de atividades; envolve refletir sobre o grau em que as crianças assumem responsabilidades, sobre a forma como os problemas são tratados e as regras são explicadas e concertadas com as crianças. Em virtude dessa análise, intervenções consequentes são ensaiadas e monitorizadas, atendendo a níveis de bem-estar emocional e de implicação.

Pensar a organização implica questionar a planificação ou as rotinas do dia "são suficientemente claras, estruturadoras e, simultaneamente, flexíveis, assegurando espaço para autonomia e segurança de todas as crianças?”. No intuito de atender às necessidades das crianças, são introduzidas variações na programação (por exemplo, períodos mais curtos no contar histórias para crianças com dificuldades de atenção; às crianças implicadas num determinado projeto e que necessitam de mais tempo para o realizar, este é-lhes dado; o mesmo para as crianças que comem mais devagar e que não podem terminar ao mesmo tempo que as outras; o período de tempo pensado para jogo no exterior é alargado; concretiza-se ou dá-se maior visibilidade às regras existentes na sala, relativamente à arrumação dos materiais, aos comportamentos permitidos e não permitidos, mediante uma sinalética específica, acordada com as crianças; introduz-se uma "tabela de áreas", para facilitar as escolhas e a visualização do número de crianças que podem estar em cada área simultaneamente).

Nesta fase 2, procede-se ainda à auscultação das opiniões das crianças sobre o jardim de infância e, em relação às crianças preocupantes, procura-se ir mais além na sua caracterização, com vista a melhor perceber o seu comportamento. Assim, nesta fase procura-se reunir um conjunto de informações sobre dados familiares, caracterização da relação da criança com os adultos e com as outras crianças, análise da implicação da criança em razão do tipo de atividades disponíveis e da sua organização (por exemplo, atividades em grande grupo, pequeno grupo, individuais, opcionais, obrigatórias, dirigi- 
das pelos adultos, não dirigidas pelo adulto) e das áreas de desenvolvimento implícitas nas atividades em que a criança evidencia baixa ou boa implicação. Também é tida em consideração a opinião da criança sobre o jardim de infância e a sua autoavaliação no que respeita às "coisas" que ela considera já ter aprendido, "coisas" em que se considera boa e "coisas" que gostaria de melhorar. Nesta linha avaliativa, procura-se caracterizar o desenvolvimento e aprendizagens das crianças de acordo com as áreas anteriormente descritas, envolvendo os pais na identificação de progressos e de próximos passos na aprendizagem/desenvolvimento das crianças e no delineamento de estratégias de apoio.

Fase 3: Em virtude das análises antecedentes, procede-se agora à clarificação de objetivos para o grupo em geral e para aquelas crianças que evidenciam níveis mais baixos de implicação e bem-estar ou que suscitam alguma inquietação. Em relação ao grupo em geral, e atendendo a aspetos como a oferta educativa, o clima de grupo, o espaço conferido à iniciativa das crianças, a organização ou mesmo características pessoais do educador (por exemplo, quão estimulante, quão sensível, quão promotor de autonomia?), o adulto é convidado a pensar em aspetos específicos de mudança e iniciativas ou ações a desenvolver com vista a alcançar os objetivos definidos. Com as crianças alvo de uma atenção acrescida, importa clarificar o melhor possível a preocupação existente em relação à criança, fazer um balanço de aspetos positivos e negativos que caracterizam a sua experiência, definir objetivos de ação e iniciativas possíveis, envolvendo os pais e/ou outros recursos da comunidade.

Neste aspeto particular da relação com as famílias e comunidade, o SAC estimula a reflexão e partillha de informação entre os vários intervenientes - pais, equipa e, se for o caso, outros profissionais - tendo em vista a adequação do processo educativo. $\mathrm{Na}$ comunicação com os pais e encarregados de educação, bem como com outros profissionais, sobre o que as crianças sabem e são capazes de fazer, o SAC reúne informação global das aprendizagens mais significativas de cada criança, realçando o seu percurso, evolução e progressos (tal como preconizado no documento Avaliação na Educação Pré-Escolar-Ministério da Educação, 2011). Neste processo, a avaliação implica uma construção partilhada (equipa, pais e outros profissionais), que passa pelo diálogo, pela comunicação de processos e de resultados, tendo em vista a criação de contextos facilitadores de aprendizagens e desenvolvimento, reunindo as características de uma avaliação "autêntica".

\section{A CONCLUIR...}

Como se refere e se conclui noutros escritos (como em Portugal; Laevers, 2010), o SAC procura dotar os educadores de conhecimentos sobre procedimentos de observação, registo e avaliação, quer dos processos, quer dos efeitos, quer da qualidade do contexto educacional da sua responsabilidade. Podemos dizer que o uso correto do SAC permite que os educadores de infância tenham uma visão clara sobre o funcionamento do grupo, atendendo aos níveis de implicação e de bem-estar, e sobre os aspetos que requerem intervenções específicas, considerando várias dimensões contextuais, como a oferta educacional, o clima de grupo, o espaço para iniciativa, a organização do contexto ou o seu próprio estilo enquanto educador. Para além de uma análise e intervenção educativa dirigida ao grupo das crianças, o SAC permite ainda a identificação das crianças que necessitam de atenção diferenciada e a consequente planificação de um conjunto de iniciativas que levem à resolução de problemas e à maximização da qualidade educativa, tanto para o grupo 
como para cada criança. Em suma, o SAC fundamenta o desenvolvimento do currículo pré-escolar e atende aos resultados da ação educativa (desenvolvimento de competências), conferindo maior estrutura e consistência ao processo de melhoria da qualidade educativa.

Uma vez desenvolvido, o ciclo contínuo de observação-avaliação e ação inerente ao SAC, as capacidades de empatia e de adoção da perspetiva da criança são reforçadas, assim como a capacidade de refletir e questionar a existência de certos hábitos e rotinas. Isso permite que o educador de infância possa procurar a inovação, experimentando outras abordagens. Se os níveis de bem-estar e implicação aumentam, os educadores sabem que estão no caminho certo, a promover e a desenvolver a autoconfiança das crianças, alimentando a sua curiosidade, motivação para a exploração e desenvolvimento de competências.

Em suma, podemos afirmar que o SAC serve os objetivos da avaliação em educação pré-escolar, permitindo conhecer as competências das crianças nos seus contextos e rotinas habituais, apoiar o delineamento de programas de intervenção e documentar o processo de desenvolvimento das crianças, assumindo-se como uma prática de avaliação alternativa e "autêntica".

Atendendo ao enquadramento oficial da avaliação em educação pré-escolar, o uso do SAC sustenta o desenvolvimento profissional ao nível da conceção e organização do ambiente educacional; observação, planificação e avaliação; relacionamentos e intervenção educacional, desenvolvimento curricular; trabalho em equipa, reflexão e capacidades de investigação (Direção-Geral..., 2001, decreto-lei n. 241/2001, de 30 de agosto - Perfil específico de desempenho profissional do educador de infância) e atende a todas as sugestões do Ministério da Educação, plasmadas quer nas OCEPE, quer nas Metas de Aprendizagem..., quer nos documentos emanados sobre Avaliação na Educação Pré-Escolar.

A finalizar, procurando alargar o contexto de análise do SAC, parece pertinente estabelecer uma relação entre a abordagem proposta nesse sistema e as recomendações da Organização para a Cooperação e Desenvolvimento Económico (OCDE) (2009), no que respeita à educação de infância. Em consonância com a primeira recomendação, o SAC coloca o bem-estar, o desenvolvimento e a aprendizagem no coração da educação de infância, respeitando a agência da criança e as suas estratégias naturais de aprendizagem. Simultaneamente, vai ao encontro de uma segunda orientação da OCDE, segundo a qual a educação de infância deve apoiar aprendizagens amplas e diversificadas, a participação e exercício da democracia pelas crianças, bem como o envolvimento das famílias, sendo que aprender a ser, aprender a fazer, aprender a aprender e aprender a viver com outros são os elementos críticos a promover em todas as crianças. A terceira sugestão da OCDE para as políticas em educação de infância refere a importância de, no contexto de orientações curriculares alargadas, os educadores e serviços educativos disporem de autonomia para planear e concretizar o currículo atendendo às particularidades das crianças ao seu cuidado, e ao objetivo da inclusão social das crianças mais vulneráveis (por exemplo, pobres, imigrantes, com dificuldades ou em desvantagem). Também essa recomendação é vivamente abraçada na abordagem SAC.

\section{REFERÊNCIAS}

Bagnato, Stephen J. The authentic alternative for assessment in early intervention: an emerging evidence-based practice. Journal of Early Intervention, Nashville, Vanderbilt University, n. 28, p. 17-22, 2005. 
. Authentic Assessment for Early Childhood Interventions: best practices. New York: The Gilford Press, 2007.

Brougère, Gilles; Vandenbroeck, Michael (Dir.). Repenser l'éducation des jeunes enfants. Bruxelles: P.I.E. Peter Lang S.A., 2007.

Bruner, Jerome. Vygotsky: a historical and conceptual perspective. In: WerTsch, James (Ed.). Culture, communication and cognition: vygotskian perspectives. Cambridge: Cambridge University Press, 1985. p. 21-34.

CArr, Margaret. Assessment in Early Childhood Settings: learning stories. London: Paul Chapman Publishing, 2001.

Carvalho, Maria Madalena Machado Mota. A avaliação no jardim de infância: contributo para o estudo da especificidade educativa do jardim de infância. 2007. Dissertação (Mestrado em Ciências da Educação, especialização em Avaliação em Educação) Faculdade de Psicologia e de Ciências da Educação, Universidade do Porto, Porto, 2007.

Drummond, Mary J. Avaliar a aprendizagem das crianças. Infância e Educação, Investigação e Práticas, Revista do GEDEI, Porto, Porto Editora, n. 7, p. 7-21, nov. 2005.

Epstein, Ann S. et al. Preschool assessment: a guide to developing a balanced approach. Preschool Policy Matters, New Brunswick: National Institute for Early Education Research, n. 7, jul. 2004.

Fernandes, Isabel Maria da Silva. O contributo da avaliação do processo de ensino- aprendizagem para a qualidade educativa na educação pré-escolar: um estudo exploratório. 2009. Dissertação (Mestrado em Ciências da Educação, na especialidade de Desenvolvimento e Aprendizagem da Criança) - Universidade de Trás-os-Montes e Alto Douro, Bragança, 2009.

Gaspar, Maria Filomena. Desafios da avaliação da matemática em educação pré-escolar. Infância e Educação, Investigação e Práticas, Revista do GEDEI, Porto, Porto Editora, n. 7, p. 47-55, nov. 2005.

Gonçalves, Isabel M. Avaliação em educação de infância, das conceções às práticas. Portugal: Editorial Novembro, 2008. (Coleção Nexus).

НАтсн, Amos J. Rethinking the relationship between learning and development: teaching for learning in early childhood classrooms. The Educational Forum, v. 74, p. 258-268, 2010. Laevers, Ferre (Ed.) The Leuven Involvement Scale for Young Children. Experiential Education Series n. 1. Leuven: Centre for Experiential Education, 1994.

. Understanding the world of objects and of people: intuition as the core element of deep level learning. International Journal of Educational Research, n. 29, p. 69-86, 1998.

. Experiential education: making care and education more effective through well being and involvement. In: LAEvers, Ferred; Heylen, Ludo (Eds.). Involvement of children and teacher style, Insights from an International Study on Experiential Education. Leuven: University Press, p. 13-24, 2003. (Studia Paedagogica, 35).

.Educação experiencial: tornando a educação infantil mais efectiva através do bem- estar e do envolvimento. Contrapontos, Revista de Educação da Universidade do Vale de Itajaí, Univali Editora, v. 4, n. 1, p. 57-69, jan./abr. 2004.

. (Ed.) et al. Well-being and Involvement in Care Settings. A Process-oriented Self-evaluation Instrument (SICs [ZIKO]). Leuven: Leuven University, Kind \& Gezin; Research Centre for Experiential Education, 2005. 
.; VAN SAnden, Peter. Pour une approche expérientielle au niveau préscolaire. Livre de base. Leuven: Centre pour un Enseignement Expérientiel, 1997. (Collection Education et Enseignement Expérientiel, n. 1).

et al. A process-oriented child monitoring system for young children. Leuven: Centre for Experiential Education, 1997. (Experiential Education Series, n. 2).

Lansdown, Gerison. La evolución de las facultades del niño. Florência: Save the Children/ UNICEF, 2005. Innocenti Insight.

Leal, Rita Alexandra Bettencourt. Formando o cidadão desde o jardim de infância: o contributo das práticas de avaliação das aprendizagens dos educadores de infância em colaboração com a família. 2011. Tese (Doutoramento em Didática e Formação) Departamento de Educação, Universidade de Aveiro, Aveiro, 2011.

Liвório, Ofélia Ascensão Oliveira Dias. Investigar com crianças na formação inicial em educação de infância. 2010. Tese (Doutoramento em Ciências da Educação) Departamento de Educação, Universidade de Aveiro, Aveiro, 2010.

Mais, Mónica M.C. Perspetivas e práticas de avaliação na educação pré-escolar: o público e o privado. In: Pequito, Paula; Pinheiro, Ana (Orgs.). Quem aprende mais? Reflexões sobre educação de infância. Porto: ESE Paula Frassinetti, 2007, p. 535-546.

Moss, Peter. Bringing politics into the nursery: early childhood education as a democratic practice. European Early Childhood Journal, v. 15, n. 1, p. 5-20, 2007.

Neisworth, John T.; Bagnato, Stephen J. The mismeasure of young children: the authentic assessment alternative. Infants and Young Children, v. 17, n. 3, p. 198-212, 2004. Oliveira, Francisca; Gaspar, Maria Filomena. Olhares sobre a avaliação em educação pré-escolar: as opiniões e as práticas dos educadores de infância. Revista Portuguesa de Pedagogia, Coimbra, Faculdade de Psicologia e de Ciências da Educação, Universidade de Coimbra, ano 38, n. 1,2,3, p. 451-484, 2004.

Oliveira-Formosinho, Júlia; Parente, Cristina. Para uma pedagogia da infância ao serviço da equidade. O portfolio como visão alternativa da avaliação. Infância e Educação, Investigação e Práticas, Revista do GEDEI, Porto, Porto Editora, n. 7, p. 22-45, nov. 2005. Pinheiro, Maria Natália. Avaliação em educação pré-escolar: perspetivas de educadoras de infância cooperantes e não cooperantes. Arquipélago - Ciências da Educação, Universidade dos Açores, Ponta Delgada, n. 10, p. 101-141, 2009.

Pinto, Jorge. A avaliação no quotidiano: uma oportunidade para a aprendizagem. Infância e Educação, Investigação e Práticas, Revista do GEDEI, Porto, Porto Editora, n. 7, p. 97-108, nov. 2005.

Portugal, Gabriela. Desenvolvimento e aprendizagem na infância. In: Conselho Nacional de Educação. A educação das crianças dos 0 aos 12 anos. Lisboa: Conselho Nacional de Educação, 2009. p. 33-67.

. Laevers, Ferre. Avaliação em educação pré-escolar: sistema de acompanhamento das crianças. Porto: Porto Editora, 2010.

. et. al. Promoting learning and development: the presence of Vygotsky's ideas in a portuguese approach to assessment in early childhood education. In: TunA, Aija; Hayden, Jacqueline (Eds.). Early childhood programs as the doorway to social cohesion: application of Vygotsky's ideas from an east west perspective. Cambridge: Cambridge Scholars Publishing, 2010. p. 109-124. 
Roldão, Maria do Céu. Gestão do currículo e avaliação de competências: as questões dos professores. Lisboa: Editorial Presença, 2003.

Sweeney, Avril. Authentic Assessment for Early Childhood Education. In: EECERA Conference - Exploring Vygotsky's Ideas: crossing borders. Praga, 29 ago.-1 set. 2007. Disponível em: <http://www.easyprague.cz/eecera2007/?level1ID=home\&level2ID=no vinka\&id=72\&lang=en $>$. Acesso em: 5 out. 2011.

Van Der Veer, René; Valsiner, Jaan. Understanding Vygotsky: a quest for synthesis. Oxford: Blackwell, 1991.

VAsconcelos, Teresa. Para uma educação de infância dos 0 aos 12 anos: integrar, articular e promover a "agência" da criança. Comunicação realizada em Aveiro, 13 dez. 2006. Disponível em: <http://psaveiro.creativethinkers.eu/images_content/Prof_Teresa.pdf〉. Acesso em: 5 out. 2011.

Vygotsky, Lev S. Psicología infantil. In: . Obras escogidas. V. IV. Madrid: Visor, 1984/1996. (Tradução em língua castelhana da edição russa de D.B. Elkonin).

Wertsch, James V.; Stone, Addison C. The concept of internalization in Vygotsky's account of the genesis of higher mental functions. In: Wertsch, James (Ed.). Culture, communication and cognition. Vygotskian perspectives. Cambridge: Cambridge University Press, 1985, p. 162-179.

\section{DOCUMENTAÇÃO E LEGISLAÇÃO}

Assembleia-Geral das Nações Unidas. Convenção sobre os Direitos das Crianças. 1989. Disponível em: <http://www.gddc.pt/direitos-humanos/textos-internacionais-dh/ tidhuniversais/dc-conv-sobre-dc.html>. Acesso em: 5 out. 2011.

Direção-Geral de Inovação e de Desenvolvimento Curricular. Decreto-Lei n. 241/2001, de 30 de agosto. Perfil específico de desempenho profissional do educador de infância. Portugal, DGIDC, 2001.

Ministério da Educação. Orientações Curriculares para a Educação Pré-Escolar. Lisboa: ME, 1997.

. Direção-Geral de Inovação e de Desenvolvimento Curricular.Metas de Aprendizagem para a Educação Pré-Escolar.2010. Disponível em: <http://www.metasdeaprendizagem.minedu.pt/educacao-pre-escolar/apresentacao/>. Acesso em: 5 out. 2011.

. Direção-Geral de Inovação e de Desenvolvimento Curricular. Circular n. 4/2011Avaliação na Educação Pré-Escolar, DGIDC/DSDC, 2011.

OECD. Education Today, the OECD Perspective. Paris: OECD Publishing, 2009.

\section{SOBRE A AUTORA}

Gabriela Portugal é doutora em ciências da educação pela Universidade de Aveiro. Professora associada da mesma instituição. E-mail: gabriela.portugal@ua.pt 


\section{GABRIELA PORTUGAL}

Uma proposta de avaliação alternativa e "autêntica" em educação pré-escolar: o Sistema de Acompanhamento das Crianças (SAC)

Neste artigo, descreve-se o contexto oficial português da avaliação em educação pré-escolar e procede-se a uma revisão de estudos e testemunhos sobre a realidade das práticas de avaliação no terreno da educação de infância, em Portugal. Atendendo às práticas avaliativas alternativas desejáveis e/ou recomendadas pela literatura da especialidade, procura-se apresentar e enquadrar conceptualmente um instrumento de avaliação denominado Sistema de Acompanhamento das Crianças (SAC), baseado no trabalho de Laevers et al. (1997), que oferece possibilidades de avaliação alternativa e/ ou "autêntica", respondendo plenamente às orientações oficiais e aos atuais consensos 
científicos sobre qualidade educativa. Finalmente, destacamos a dinâmica e alguns efeitos gerados pelo seu uso na intervenção educacional.

Palavras-chave: avaliação autêntica; educação pré-escolar; Sistema de Acompanhamento das Crianças; bem-estar e implicação; desenvolvimento de competências; intervenção educacional.

\section{Proposal of an alternative and "authentic" assessment in early childhood education: Children Follow-up Instrument}

In this article, we describe the context of the Portuguese official evaluation in pre-school and review a number of studies and testimonies about the reality of assessment practices in the field of early childhood education in Portugal. Given the desirable alternative assessment practices recommended in literature from this field, we intend to present a conceptual framework and assessment tool called Children Follow-up Instrument, based on the work of Laevers et al. (1997), which offers possibilities for alternative assessment and or "authentic" assessment, fully complying with the official guidelines and current scientific consensus on quality education. Finally, we highlight the dynamics and some of the effects generated by its use in educational intervention.

Keywords: authentic assessment; pre-school education; children follow-up instrument; well-being and involvement; competencies development; educational intervention.

\section{Una propuesta de evaluación alternativa y "auténtica" en educación preescolar: el Sistema de Acompañamiento de los Niños}

En este artículo, se describe el contexto oficial portugués de la evaluación en educación preescolar y se procede a una revisión de estudios y testimonios sobre la realidad de las prácticas de evaluación en el terreno de la educación de infancia, en Portugal. Atendiendo a las prácticas evaluativas alternativas recomendadas por la literatura de la especialidad, se busca presentar y encuadrar conceptualmente un instrumento de evaluación denominado Sistema de Acompañamiento de los Niños, basado en el trabajo de Laevers et al. (1997), que ofrece posibilidades de evaluación alternativa y/o "auténtica", respondiendo plenamente a las orientaciones oficiales y a los actuales consensos cientificos sobre calidad educativa. Finalmente, destacamos la dinámica y algunos efectos generados por su uso en la intervención educacional.

Palabras clave: evaluación auténtica; educación preescolar; sistema de acompañamiento de los niños; bienestar e implicación; desarrollo de competencias; intervención educacional. 